\title{
ORIGINAL ARTICLE \\ The effect of continuous care model on infant sleep habits in Bint Al- Huda educational and medical center in Bojnourd in 2019
}

\author{
MARYAM YAZDANI ${ }^{1}$, MOHAMMAD HOSSEIN HAKIMI ${ }^{2}$, KIMIAGILAK $^{3}$, FATEMEH JAFARI ${ }^{* 4}$, MAHSA KAZEMI ${ }^{5}$ \\ ${ }^{1}$ Department of Nursing, Aliabad Katoul Branch, Islamic Azad University, Aliabad Katoul. Iran \\ ${ }^{2}$ Department of Nursing, School of Nursing and Midwifery, Ardabil University of Medical Sciences, Ardabil, Iran \\ ${ }^{3}$ MSc Student in Psychiatric Nursing, Faculty of Nursing and Midwifery, Student Research Committee, Mazandaran University of Medical \\ Sciences, Sari, Iran \\ ${ }^{4}$ Department of Nursing, Aliabad Katoul Branch, Islamic Azad University, Aliabad Katoul. Iran \\ ${ }^{5}$ MSc Student in Psychiatric Nursing, Faculty of Nursing and Midwifery, Student Research Committee, Mazandaran University of Medical \\ Sciences, Sari, Iran \\ Correspondence to: *Fatemeh Jafari. Department of Nursing, Aliabad Katoul Branch, Islamic Azad University, Aliabad Katoul. Iran. \\ Email:oneid33@yahoo.com
}

\begin{abstract}
Background: Sleep is one of the essential and vital needs of human and a factor that affects the growth and development of children. The basic learning of sleep habit is formed in childhood and the person tries to maintain it throughout life. Therefore, considering the importance of childhood in the formation of appropriate sleep habit, this study was conducted to investigate the effect of continuous care model on infant sleep habits in Bint Al-Huda medical center in Bojnourd.

Methods: This interventional study was performed on 66 mothers attending the Bint Al-Huda Hospital in Bojnourd in 2019. Sampling was done by available method and the samples were randomly assigned to the intervention and control groups. The intervention group received a continuous care model program in 4 sessions. Each session lasted for of 45-60 minutes. Data collection tools included the demographic characteristics questionnaire and the Infant Sleep Habit Scale (ISQ). The collected data were analyzed by SPSS software version 16 using Fisher and Rapid Major statistical tests at the significance level of $p<0.05$.

Results: The results of Rapid Major test showed a significant difference $(P=0.01)$ between the intervention and control groups at 1,2 and 3 months after the intervention, so that sleep habits did changed in the intervention group at different times after the intervention, but in the control group, sleep habit disorders were observed.

Conclusion: According to the obtained results, it is suggested that teaching mothers proper sleep habits in the long run can improve their knowledge and performance in improving sleep habits of their infants.

Key words: Continuous Care Model, Sleep Habits, Infant
\end{abstract}

\section{INTRODUCTION}

The most sensitive stage of a child's development is the period of infancy, and an important part of the child's growth and development takes place in this period [1]. During this period, breast milk is the best food for infants [2], as it provides all the necessary nutrients and fluids for the growth and health of the child [3]. In addition, sleep is one of the most important behaviors that play an important role in human health [4]. Numerous studies have shown that sleep stimulates the release of growth hormone and promotes the children development, weight gain and better growth, which are especially important in childhood [5]. During childhood, the infancy is the most important period for the development of sleep problems [6]. The need for sleep in humans varies and depends on various factors such as age, genetic background, and physical and mental states, so that sleep from the age of 6 weeks is about 14 to 16 hours a day, and reduces to 12 to 14 hours a day at the age one [7]. Sleep quality plays an important role in adaptation and health promotion [8]. Sleep disorders cause fatigue and threaten health [9]. Learning incorrect sleeping habits also affects the adult life and endangers the health of individuals and society. Also, inappropriate sleeping habits and behaviors will cause the child to suffer from complications such as irritability, aggression, headache, digestive disorders, etc. [10]. On the other hand, sleep habits are formed by the end of childhood and parents have an important role in this formation [11]. Improper sleeping habits (sleeping late at night and waking up late in the morning) and some sleep problems are caused by physical, psychological, environmental or hereditary conditions that reduce the amount of proper sleep and endangers the health of the child and even his/her family [12]. But what is certain is that, a regular and good sleeping habit will facilitate the sleep process and the person feels relaxed after waking up. Experts believe that most sleep problems can be solved by following proper sleep habits [9]. Sleep habits include behaviors related to when to go to bed, waking up, how long to sleep at night, taking sleeping pills, drinking at night, etc [13]. In general, people follow unique sleeping habits and patterns [14]. The foundations of learning these habits are formed in childhood according to cultural and family contexts and the person follows them throughout his/her life [15]. On the other hand, establishing order and regulation in relation to various aspects of sleep, including sleep hours and maintaining them, improves the quality of sleep [16]. Among these, one of the patterns that increase the quality of sleep is the continuous care model [17]. Continuous care is a regular process to establish effective, interactive and consistent communication between the client and caregivers in order to identify the needs and problems and sensitize clients to accept ongoing health behaviors to improve and promote their health [18]. Applying this model helps to correctly identify the patient's problems, and motivate the patient and his/her family to solve the problem [19]. Some of the basic 
functions of continuous care model include recognizing actual and potential problems related to the disease, accepting the disease and its effects on life, investing in maintaining health and valuing it, family involvement, managing current and immediate issues, and noticing changes in lifestyle and pattern [20]. The use of empowerment programs will have an important impact on the quality of care provided by parents [18]. However, the effect of continues care model on maternal perception of infant sleep habits has not been evaluated. Therefore, this study was performed to determine the effect of continues care model on infant sleep habits in Bint Al-Huda medical center in Bojnourd.

\section{METHODS AND MATERIALS}

This interventional study with pre-test / post-test design was conducted in two groups of intervention and control. The statistical population of this study consisted of mothers attending Bint Al-Huda Medical Center in Bojnourd. In order to determine the sample size, we used $G^{*}$ POWER software based on the Narengi's article with an effect size of 0.92 and $95 \%$ test power, and calculated 66 people (33 in the intervention group and 33 in the control group). Significant level of 0.05 was considered in this study [21].

Inclusion criteria were; willingness to participate in the study, ability of mothers to read and write, no physical or mental problems of the studied infants, mothers who gave birth to their first child at the Bint Al-Huda Educational and Medical Center in Bojnourd in 2019. Also, non-participation of mothers in educational sessions, mothers' withdrawal from study, and mothers who had two or more children were among the exclusion criteria.

A total of 66 mothers were randomly assigned into the intervention and control groups. For this purpose, mothers attending Bint Al-Huda Educational and Medical Center in Bojnourd, who met all the inclusion criteria, were considered as a research sample after obtaining informed consent from them.

The instruments used in this study included the demographic characteristics questionnaire for measuring items such as gender, mother's age, father's age, mother's job, father's job, mother's education, father's education, and economic status, and the infant sleep habits questionnaire (ISQ). The ISQ was developed in 1999 by Jorlin Morrell. This tool contains of 10 questions and for each question six answers are considered and each answer is given a score. Each question of the questionnaire is given a score of 0 (strongly disagree), 1 (relatively disagree), 2 (slightly disagree), 3 (slightly agree), 4 (relatively agree) and 5 (strongly agree). The overall score ranges from 0 to 38 with higher score indicating the mother's more negative doubts and concerns. In Morrell's study, Cronbach's alpha coefficient of 0.82 was obtained for the questionnaire, and the correlation coefficient of retest after two to four weeks was 0.92. Simultaneous validity of the questionnaire was confirmed using Composite Score and Richman's Sleep Note (1981), which indicated its validity in assessing sleep problems in young children. In regard to the Richman's Sleep Note Scale, high levels of sensitivity and specificity have been reported. In the study of Mohsenian et al (2014), Cronbach's alpha coefficient of 0.68 was obtained [22].

Demographic and sleep habits questionnaires were completed in both groups before the intervention, when a brief explanation was provided to the intervention group. Then, based on the continuous care model, an educational program related to child sleep (definition of sleep, types of children's sleep, importance of sleep, appropriate duration of infant sleep, appropriate sleep strategies, factors affecting sleep) was provided for the intervention group in 4 sessions (60 minutes each) according to Table 1. Then, the mothers in the intervention and control groups completed the questionnaires at one month, two months and three months after childbirth. During this period, no interventions were performed for the control group and only the pretest was done. At the end of the program, a post-test was carried out. (Diagram 1)

The sample selection process was such that after explaining the purpose and method of the study to the mothers, they were invited to participate in the research and if they agreed, the written and oral informed consent form was completed by them. The mothers were also reassured that their non-participation in the study would not prevent them from receiving the center's routine services. They were also informed that if they do not want to continue to participate in the study, they can leave the study without any problems. In addition, they were assured of the confidentiality of their personal information, and accuracy and scientific reliability in recording information and statistics obtained at the time of data collection and analysis. In order to observe ethical issues, after collecting information, educational materials were provided to the control group.

The SPSS statistical software version 16 was used to analyze the data. Frequency, percentage, mean and standard deviation were also used to describe the data and Fisher's exact and Rapid Major tests were used to analyze the data.

Table 1- Training sessions

\begin{tabular}{|c|c|c|c|}
\hline Educational contents & Dimensions & Time & Session \\
\hline $\begin{array}{l}\text { Familiarity with the work process and goals of the group. Familiarity with the mothers under study and } \\
\text { establishing communication and mutual trust between the researcher and mothers. }\end{array}$ & Familiarity & $15 \mathrm{~min}$ & 1 \\
\hline \multicolumn{4}{|l|}{ Determining the intervention and control group by the researcher } \\
\hline Familiarity with the baby's natural physiological changes & Physiologic & $15 \mathrm{~min}$ & 2 \\
\hline $\begin{array}{l}\text { Familiarity with common problems and obstacles of baby's sleep and creating the correct sleeping } \\
\text { habits in the infant }\end{array}$ & Evaluation & $15 \mathrm{~min}$ & 3 \\
\hline \multicolumn{4}{|c|}{ At the end of the third session, an educational pamphlet was provided to mothers to better learn the content. } \\
\hline $\begin{array}{l}\text { Completion of questionnaires one month, two months and three months after the intervention by two } \\
\text { intervention and control groups - Evaluation: At this stage, after two months of continuous } \\
\text { intervention, the data were the data from Sleep Quality Questionnaire were collected, and the results } \\
\text { were compared between the study groups. }\end{array}$ & $\begin{array}{l}\text { one month, two months and } \\
\text { three months after the } \\
\text { intervention }\end{array}$ & $15 \mathrm{~min}$ & 4 \\
\hline
\end{tabular}




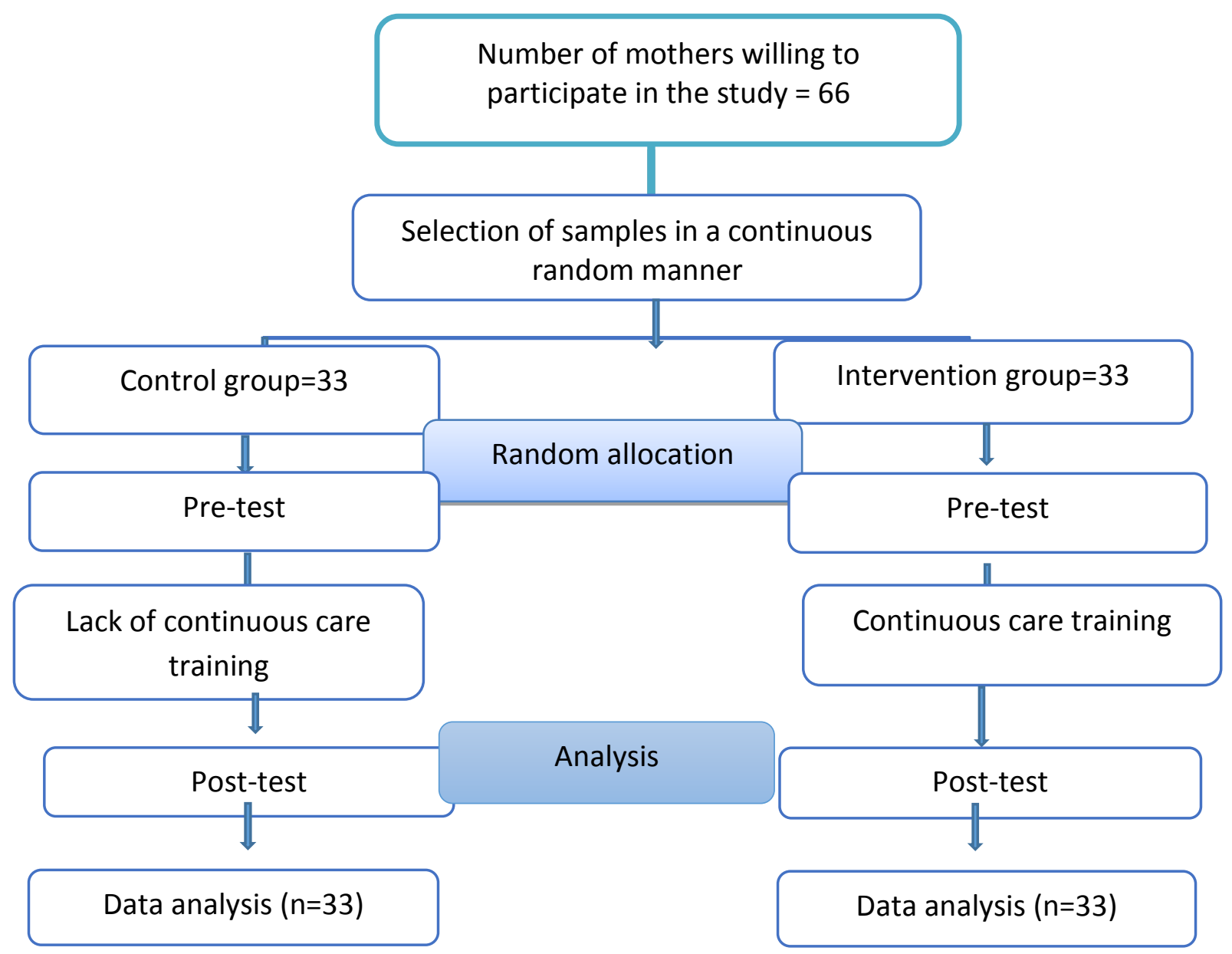

\section{Chart 1-Concert chart}

\section{RESULTS AND DISCUSSION}

Comparison of demographic characteristics showed that 15 infants (45\%) in the interventional group and $17(52 \%)$ in the control group were female, and 18 infants $(55 \%)$ in the interventional group and $16(48 \%)$ in the control group were male. Chi-square test did not show a significant difference between the two groups in that regard $(p=0.4)$. Also, Fisher's exact test did not show a significant difference between the two groups in terms of mother's age $(p=$ $0.12)$, father's age $(p=0.38)$, mother's job $(p=0.59)$, father's job $(p=0.23)$, mother's education and father's education $(p=0.36)$.

As shown in Table 3, Rapid Major test showed a significant difference between the intervention and control groups at different times $(P=0.01)$, so that sleep habits did not change at different times in the intervention group, but impaired sleep habits was observed in the control group.

Due to the importance of infant sleep habits, the present study was conducted to determine the effect of continuous care model on infant sleep habits in Bint AlHuda Hospital in Bojnourd. The findings of this study showed a significant difference between the intervention and control groups at different times, so that no change in sleep habits was observed in the intervention group at different times, but sleep disorders we observed in the control group. Family behavioral habits may affect the place, time, and quality of sleep in children. In many cases, children follow the parental behavior pattern. Sadeh et al., believed that with increasing irregular sleep time of parents and their delayed sleep, incorrect sleeping habits also increase in children [23]. Therefore, correcting family behavioral habits can improve children's sleep disorders. Behaviors such as self-control, stability and parental responsibility affect children's behavior, and usually parents' emotional responses lead to children's comfort [24]. Parents' close and intimate relationship with children plays an important role in improving children's sleep by relieving emotions and reducing stress [25]. In line with this study, Ivadra et al (2013) in Japan studied school aged children and concluded that, the mean score of sleep disorders in these children was $40.0 \pm 6.5$ and the most sleep disorders were related to sleep behavior [26]. Cruz et al. (2016) reported a mean score of sleep disorder in Spanish children at $43.1 \pm 7.25$ [27]. In the study of Van Litsenberg et al (2010), the most common sleep disorders were related to daily drowsiness [28]. Also, the results of 
Khazaei et al (2013) study showed that social support has an important role in life habits and plans [29]. Mishra et al. (2017) studied the sleep habits of primary school children and referred to its effect on sleep patterns [30]. In the study of Francis (2016), the score of sleep quality index was recorded in three rounds and scores of the first, second and third rounds were reduced from 12 to 10 and then to 8 , respectively [31]. Parents play an important role in providing supportive care to their children [32]. Therefore, it can be said that parental education has an important role in reducing stress and the quality of care provided to children $[33,34]$.

Table 2: The effect of continuous care model on infants' sleep habits

\begin{tabular}{|l|l|l|l|l|l|l|}
\hline \multicolumn{2}{|c|}{ Time } & Before intervention & 1 month after intervention & 2 months after intervention & 3 months after intervention & P-Value \\
\hline $\begin{array}{l}\text { Sleep } \\
\text { habit }\end{array}$ & Intervention & $30.33 \pm 4.59$ & $30.93 \pm 7.01$ & $29.42 \pm 8.52$ & $29.42 \pm 8.52$ \\
\cline { 2 - 5 } & Control & $28.03 \pm 6.01$ & $34.9 \pm 6.56$ & $32.6 \pm 8.33$ & $32.6 \pm 8.39$ \\
\hline
\end{tabular}

\section{CONCLUSION}

In general, the results of this study showed that the continuous care model has an important role in infants' sleep habits. Therefore, this care model can be used to improve the quality of children's sleep.

Author's contribution: All authors contributed for preparing and finalization of this article.

Acknowledgement: The present article is part of a master's degree thesis in pediatric nursing at the Islamic Azad University, Aliabad Kotoul Branch, with the number: ID IR.IAU.CHALUS.REC.1398.042. We would like to thank all those who helped us in this project.

Funding: We have no funding source for this project.

Declaration of Conflicting Interests: All the authors declare that there is no conflict of interest for this project

Data availability: The data that support the findings of this study are available from the corresponding author, upon reasonable request.

\section{REFERENCES}

1. Nasirzadeh R, mazaheri ma. Comparison of temperament of infants with and without feeding problems. Sadra medical sciences journal. 2017;5(1):-.

2. Kennedy D, Isaacs D. Breast is best. Journal of Paediatrics and Child Health. 2013;49(9):789https://doi.org/10.1111/jpc.12375.

3. Jafari F, Farahrooz H, Abyar Z, Tadayyon B, Azami F. The Relationship Between Duration of Breastfeeding and Maternal Factors. Journal of Fasa University of Medical Sciences. 2015;5(2):202-9 http://journal.fums.ac.ir/article-1386-en.html.

4. Gregory AM, Sadeh A. Sleep, emotional and behavioral difficulties in children and adolescents. Sleep medicine reviews.

https://doi.org/10.1016/j.smrv.2011.03.007.

5. Owens J. Classification and epidemiology of childhood sleep disorders. Primary care. 2008;35(3):533-46, vii https://doi.org/10.1016/j.pop.2008.06.003.

6. Yati $\mathrm{M}$, Wahyuni $\mathrm{S}$, Islaeli I. THE EFFECT OF STORYTELLING IN A PLAY THERAPY ON ANXIETY LEVEL IN PRE-SCHOOL CHILDREN DURING HOSPITALIZATION IN THE GENERAL HOSPITAL OF $\begin{array}{lll}\text { BUTON. } 2017 . & 2017 ; 3(3): 6\end{array}$ https://doi.org/10.36685/phi.v3i3.134.

7. Quach J, Hiscock H, Wake M. Sleep problems and mental health in primary school new entrants: cross-sectional community-based study. J Paediatr Child Health. 2012;48(12):1076-81 https://doi.org/10.111/j.440754.2012.02466.x.

8. Hojjati. H, Ebadi A, Akhoondzadeh G, Zarea. K, Sirati M, Heravi M et al. Sleep Quality in Spouses of War Veterans with Post-Traumatic Stress: A Qualitative Study. MCS. 2017; $4(1): 1-9$

9. Hamid Hojati,Shamsolmolok Jalalmanesh,Mohammad Fesharaki .Sleeplessness effect on the general health of hospitals nightshift nurses in Gorgan, Iran. J Gorgan Univ Med Sci. 2009; 11 (3) :70-75.

10. Dalvandi A, Haj Hashim Khani MAz, Hasandoost F, Javadi M. Relationship between BMI, maternal health promoting lifestyle and demographic variables among Schoolchildren in Qazvin, 2014. Iranian Journal of Pediatric Nursing. 2017;4(2):44-50 https://doi.org/10.21859/jpen-04027.

11. Jalilolghadr $S$, Hashemi $S$, Javadi $M$, Esmailzadehha $N$, Jahanihashemi $\mathrm{H}$, Afaghi A. Sleep habits of Iranian preschool children in an urban area: Late sleeping and sleep debt in children. Sleep and Biological Rhythms. 2012;10(2):154-6 https://doi.org/10.1111/j.4798425.2011.00516.x.

12. Hajhashemkhani MA, Dalvandi A, Kashaninia Z, Javadi M, Biglarian A. The Relationship between Family Health Promoting Lifestyle and Sleep Habits in Children 6 to 11 Years old. Journal of Mazandaran University of Medical Sciences. 2015;25(127):92-9.

13. Sweileh WM, Ali IA, Sawalha AF, Abu-Taha AS, Zyoud SH, Al-Jabi SW. Sleep habits and sleep problems among Palestinian students. Child and adolescent psychiatry and mental health. 2011;5(1):25 https://doi.org/10.1186/7532000-5-25.

14. Javadi M, Javadi A, Kalantari N, Jaliloghadr S, Mohamad H. Sleep Problems among Pre-School Children in Qazvin, Iran. Malays J Med Sci. 2014;21(6):52-6 https://pubmed.ncbi.nlm.nih.gov/25897283

https://www.ncbi.nlm.nih.gov/pmc/articles/PMC4391455/.

15. Shamsaei F, Darayi M, Ahmadinia H, Seif M, Khalili A. Sleep Habits of Primary School Students of Nahavand City From the Point of View of Parents. Qom Univ Med Sci J. 2018;12:78-85 https://doi.org/10.29252/qums.12.8.78.

16. Rahimi A, Ahmadpanah $M$, Shamsaei $F$, Cheraghi $F$, Sadeghi Bahmani D, Holsboer-Trachsler E, et al. Effect of adjuvant sleep hygiene psychoeducation and lorazepam on depression and sleep quality in patients with major depressive disorders: results from a randomized three-arm intervention. Neuropsychiatr Dis Treat. 2016;12:1507-15 https://doi.org/10.2147/NDT.S110978.

17. Mohmadi S, Hojjati $\mathrm{H}$. The effect of continuous care model on sleep quality in veterans with post-traumatic stress disorder referred to psychiatric clinics of Alborz province. J Mil Med. 2019; 21 (4) :418-424

18. Hanieh Sajadi, Golbahar Akhoundzadeh, Hamid Hojjati. (2020). The Effect of Empowerment Program on Participation of Mothers with Premature Infants Hospitalized in Neonatal Intensive Care Unit of Sayyed Shirazi Hospital in Gorgan, in 2018. Indian Journal of Forensic Medicine \& Toxicology, 14(2), https://doi.org/10.37506/ijfmt.v14i2.3082
1269-1276. 
19. Sadeghi $H$, Azizzadeh Forouzi $M$, Haghdoust $A A$, Mohammad Alizadeh S. EFFECT OF IMPLEMENTING CONTINUOUS CARE MODEL ON SLEEP QUALITY OF HEMODIALYSIS PATIENTS. IRANIAN JOURNAL OF CRITICAL CARE NURSING (IJCCN). 2010;3(1):13-8.

20. Moosavinasab SMM, Vahedian-Azimi A, Salesi M, Vahedi E, Karimi Zarchi AA, KhoshFetrat M, et al. A Review of 17 Years of Application of a Continuous Care Model on the Consequences of Acute and Chronic Diseases: Describing and Assessing the Quality of Methodology of Papers. Journal of Military Medicine. 2018;20(1):27-55 http://militarymedj.ir/article-1-1908-fa.html.

21. Narenji F, Rosbahany N. The effects of massage therapy on weight gain and sleep behaviors in infants. Koomesh journal. 2008;9(4):279-84.

22. Mohsenian E, Tabibi Z, Mashhadi ALI. SETTLING TO SLEEP STRATEGIES AND SLEEPING PROBLEMS AMONG 1-2 YEAR OLD INFANTS. DEVELOPMENTAL PSYCHOLOGY (JOURNAL OF IRANIAN PSYCHOLOGISTS). 2014;10(39):237-48.

23. Sadeh A, Raviv A, Gruber R. Sleep patterns and sleep disruptions in school-age children. Developmental psychology. 2000;36(3):291-301 https://doi.org/10.1037//0012-1649.36.3.291.

24. Hysing M, Sivertsen B, Stormark KM, Elgen I, Lundervold AJ. Sleep in children with chronic illness, and the relation to emotional and behavioral problems--a population-based study. Journal of pediatric psychology. 2009;34(6):665-70 https://doi.org/10.1093/jpepsy/jsn095.

25. Ozgoli G, Sheikhan Z, Soleimani F, Nasiri M, Mirzaee S, Kavousi F, et al. A Study of EffectiveFactors on Sleep Disorders in 4-6Years old Children in Tehran City, Iran. muqjournal. 2015;9(5):50-60.

26. Yoshitaka I, Yuichi K, Arata O, Yuriko D, Masahide U, Masaki K, et al. Study of the sleep patterns, sleep habits, and sleep problems in Japanese elementary school children using the CSHQ-J. The Kitasato medical journal. 2013;43:31-7.

27. Lucas-de la Cruz L, Martínez-Vizcaino V, Álvarez-Bueno C, Arias-Palencia N, Sánchez-López M, Notario-Pacheco B. Reliability and validity of the Spanish version of the Children's Sleep Habits Questionnaire (CSHQ-SP) in school- age children. Child: care, health and development. 2016;42(5):675-82 https://doi.org/10.1111/cch.12357.

28. van Litsenburg RR, Waumans RC, van den Berg G, Gemke RJ. Sleep habits and sleep disturbances in Dutch children: a population-based study. European journal of pediatrics. 2010;169(8):1009-15 https://doi.org/10.7/s00431-010-11698.

29. Soudabeh Aloustani, Karvan Bekmaz, Adeleh Sadeghloo, Hamid Hojjati. (2020). The Comparison of Social Support Against the Life Quality of The Spinal Cord Injury Under Stress . Indian Journal of Forensic Medicine \& Toxicology, 14(2), https://doi.org/10.37506/ijfmt.v14i2.3221

30. Mishra A, Pandey RK, Minz A, Arora V. Sleeping habits among school children and their effects on sleep pattern. J Caring Sci. 2017;6(4):315-23 https://doi.org/10.15171/jcs.2017.030.

31. Dietrich SK, Francis-Jimenez CM, Knibbs MD, Umali IL, Truglio-Londrigan M. Effectiveness of sleep education programs to improve sleep hygiene and/or sleep quality in college students: a systematic review. JBI database of systematic reviews and implementation reports. 2016;14(9):108-34 https://doi.org/10.11124/jbisrir-2016003088.

32. Hosseini N, Akhoundzadeh G, Hojjati H. The effect of childparent relationship therapy on social skills of Preschool Children: a semi-experimental study. International Journal of Adolescent Medicine and Health. 2019. DOI: 10.1515/ijamh2019-0151

33. Yazarloo, M., Hojjati, H., Gharebagh, Z.A. The effect of spiritual self-care education on stress of mothers of premature infants admitted to NICU of hospitals affiliated to golestan university of medical sciences. Pakistan Journal of Medical and Health Sciences, 2020, 14(3), pp. 1615-1619

34. Hekmati Pour N, Mahmoodi-Shan GR, Ebadi A, Behnampour N. Spiritual self-care in adolescents: a qualitative study. Int J Adolesc Med Health. 2020 Oct 16:/j/ijamh.ahead-of-print/ijamh-2019-0248/ijamh-2019-

0248.xml. doi: 10.1515/ijamh-2019-0248. Epub ahead of print. PMID: 32083447. 